\title{
Battery Thermal Management System
}

\author{
Omkar Kapkar ${ }^{1}$, Siddhi Kanade ${ }^{2}$, \\ Pallavi Kamble ${ }^{3}$, Tushar Kamble ${ }^{4}$ \\ Department of Electrical Engineering \\ P.E.S. Modern College of Engineering \\ Shivajinagar Pune-05, Maharashtra, India
}

\author{
Prof. Sonali Mahajan \\ (Project Guide) \\ PES Modern College of Engineering \\ Shivajinagar Pune-05, Maharashtra, India
}

\begin{abstract}
A design for the thermal management of Lithium-ion battery packing as utilized in hybrid and electric vehicles has been developed. The design satisfies almost all thermal and physical issues relating to the battery operating temperature range, volume and the battery cycle life. Particular attention was given to the thermal management of batteries operating in extreme conditions, that is, $-50^{\circ} \mathrm{C}$ to $+50^{\circ} \mathrm{C}$, with desired operating conditions held between $0^{\circ} \mathrm{C}$ to $35^{\circ} \mathrm{C}$. The cooling method here could be thought to heat sink approach with heat removed using water. The main goal of a battery thermal management system is to maintain a battery pack at an optimum average temperature, as dictated by life and performance trade-off. It is important that an even temperature, perhaps with small variations is maintained between cells and within the pack. While designing such systems, one should also consider that the battery pack should be compact, lightweight, have low cost of manufacturing, and have easy access for maintenance. The battery thermal management system should also allow the pack to work under a good range of climatic conditions and supply ventilation, if the battery generates potentially hazardous gases. What is important is that the control of temperature between acceptable limits, and a good uniformity of temperature across each cell.
\end{abstract}

Key Words: Thermal management, Cooling, Lithium-ion battery pack, Temperature, Cells, Liquid-cooled.

\section{INTRODUCTION}

Large variations in temperature of batteries causes reduction in life span \& power of battery. It also reduces working of electrochemical systems \& efficiency of battery. For example, as temperature falls below $-10^{\circ} \mathrm{C}$, the performance of Li-ion batteries deteriorates severely [1], while at high temperature, these types of batteries are prone to uncontrolled temperature build-up [2]. Hence there's a requirement of using battery thermal management system in high voltage battery pack.

For battery packs it's important to manage the pack to stay within the desired temperature range for optimum performance and life, and also to scale back uneven distribution of temperature throughout a pack which might cause reduced performance. If a battery is operated outside of its operating temperature range, then battery thermal management system will always include an indoor switch. This would prevent fire or explosion risk, but the battery also becomes temporarily unavailable. A number of works have reported that Li-ion battery calendar life [3] and cycle life [4] degrade quickly if kept or used at high temperature.

A well-designed battery thermal management system will ensure good battery performance, safety and better capacity. Methods like liquid cooling (indirect or direct; passive or active), air cooling (natural or forced), cooling with the help of phase change materials, or combination of them have been used. Natural air cooling or forced air cooling can't provide uniform temperature to battery pack [5],[6]. By using indirect active liquid cooling method, a large amount of heat can be dissipated compare to natural air cooling or forced air cooling. Some ventilation should always be provided for the passing out potentially hazardous gases generated by batteries. However, it's desirable to stay the cooling fluid break away the battery then for little battery packs, cooling by fluid might not actually be possible. It is known that the desired operating temperature for most $\mathrm{Li}$-ion batteries is $0^{\circ} \mathrm{C}$ to $35^{\circ} \mathrm{C}$, although ambient temperatures can vary from$50^{\circ} \mathrm{C}$ to $50^{\circ} \mathrm{C}$.

\section{DESIGNING IN COMSOL MULTIPHYSICS}

The design of the Liquid cooled lithium-ion battery pack was analyzed using COMSOL Multiphysics Software. The model solves in 3D. This model simulates a temperature profile in a number of cells and cooling fins in a liquid cooled lithium-ion battery pack. The model is based on two assumptions: The first one is that the material properties of the cooling fluid and battery material can be calculated using an average temperature for the battery pack, and the second one is that the variations in heat generation during the load cycle are significantly slower than the heat transport within the battery pack. The first assumption is valid if the temperature variations in the battery pack are small. The second assumption implies that the thermal balance is quasi-stationary for the given battery heat source and at a given operational point during the load cycle.

\subsection{Construction}

Basically, the design consists of a model of six lithium-ion prismatic cells in series, placing three coolant plates in between group of two cells each, in order to cool the cell temperature by flowing of coolant from cooling fins present in coolant plates. In this design water is used as coolant.

The repetitive unit cell of the battery pack consists of two prismatic batteries and a cooling fin plate with five flow cooling channels, with one battery on each side, see Figure 1. The cooling fins and batteries are 2 $\mathrm{mm}$ thick each, summing up to a total unit cell thickness of $6 \mathrm{~mm}$. The overall volume of one cell is $(100 * 2 * 100)$ mm (depth*width*height). 


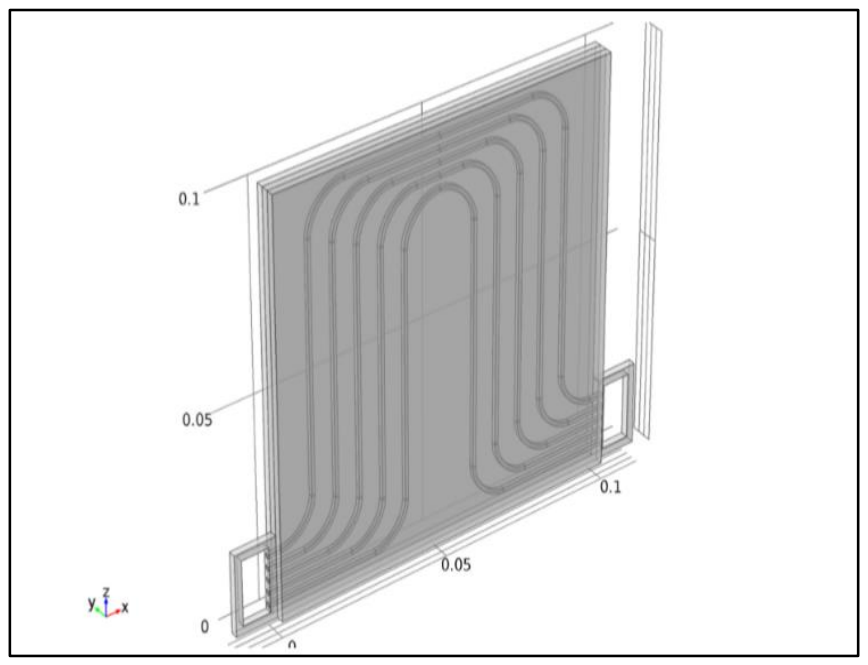

Fig -1: Unit cell of the battery pack.

The modeled battery pack geometry consists of total no. of six cells, three stacked unit cells and two flow connector channels: one on the inlet and one on the outlet side of the cooling fins, see Fig -2. The geometry represents the last cells towards the outlet end of a battery pack. The overall volume of battery pack is $(100 * 15 * 100) \mathrm{mm}$ (depth*width*height). For better understanding of geometry of design, refer Fig -3 , Fig -4 , Fig -5, Fig -6.

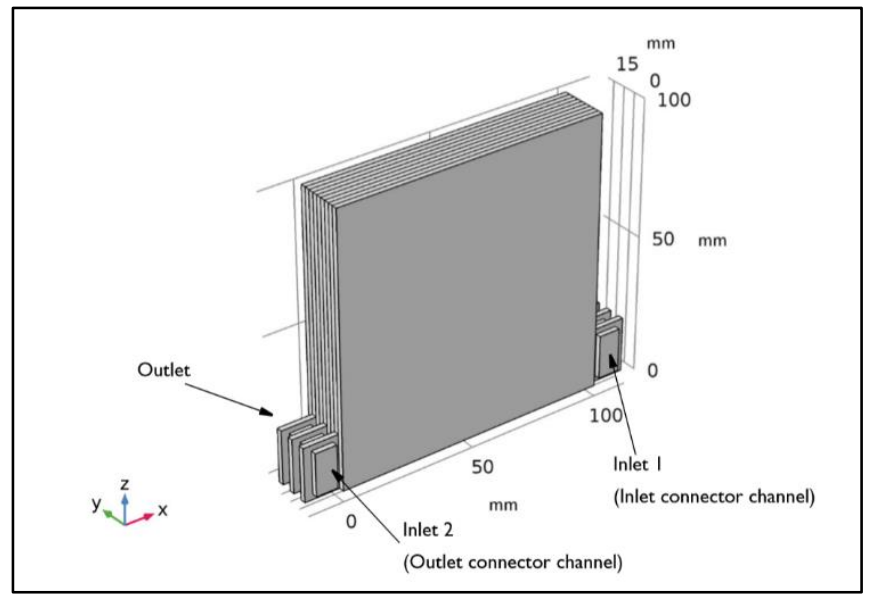

Fig -2: Battery pack geometry.

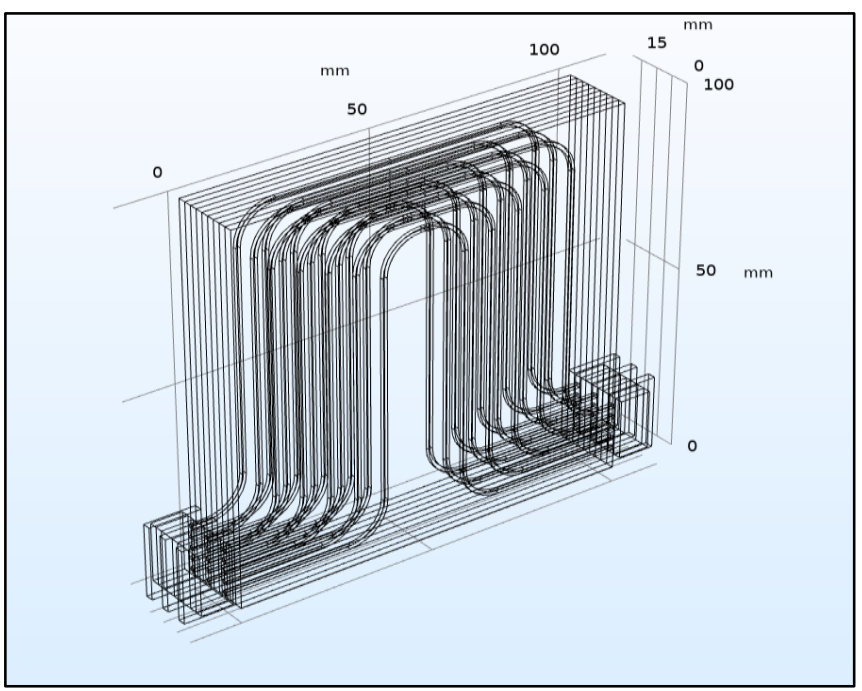

Fig -3: structure of battery pack with cooling fins present in it.

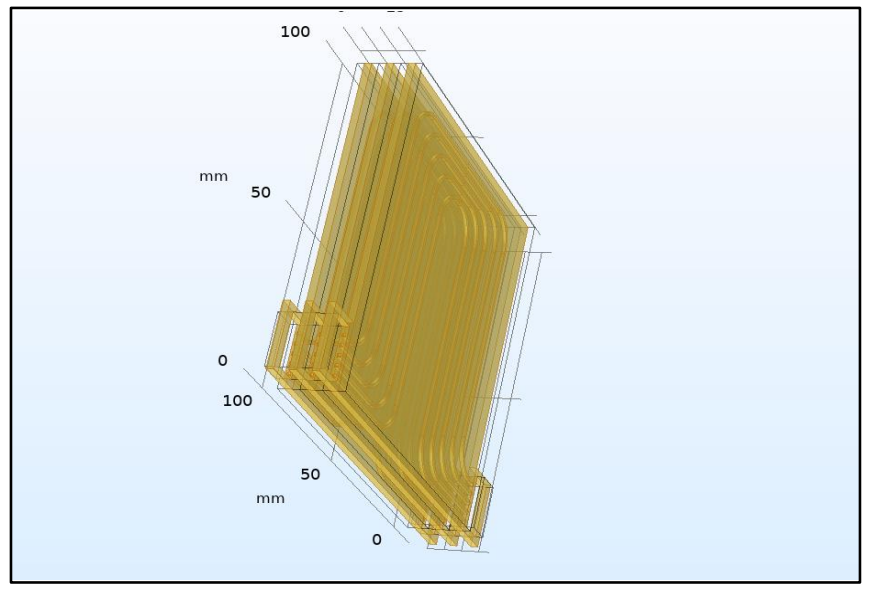

Fig -4: Shows geometry of cooling fins.

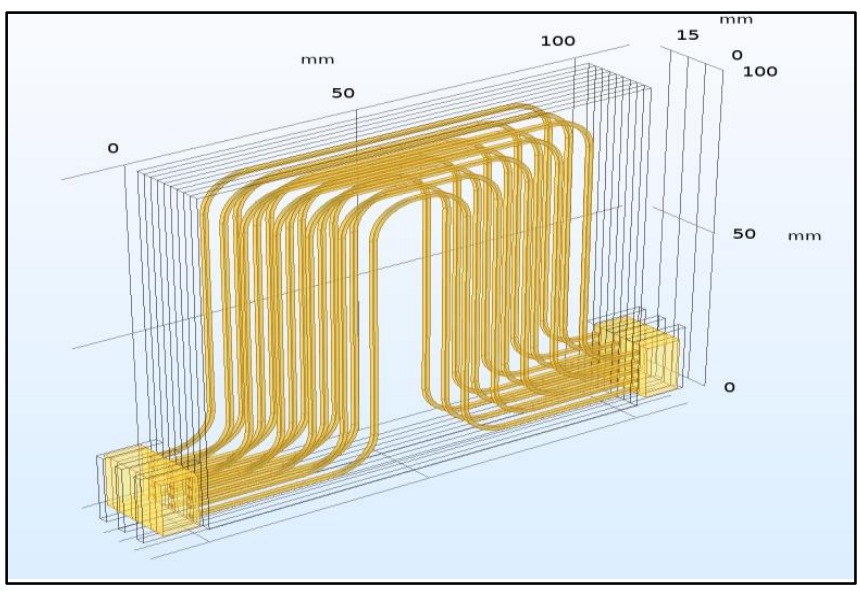

Fig -5: Shows geometry of flow compartment.

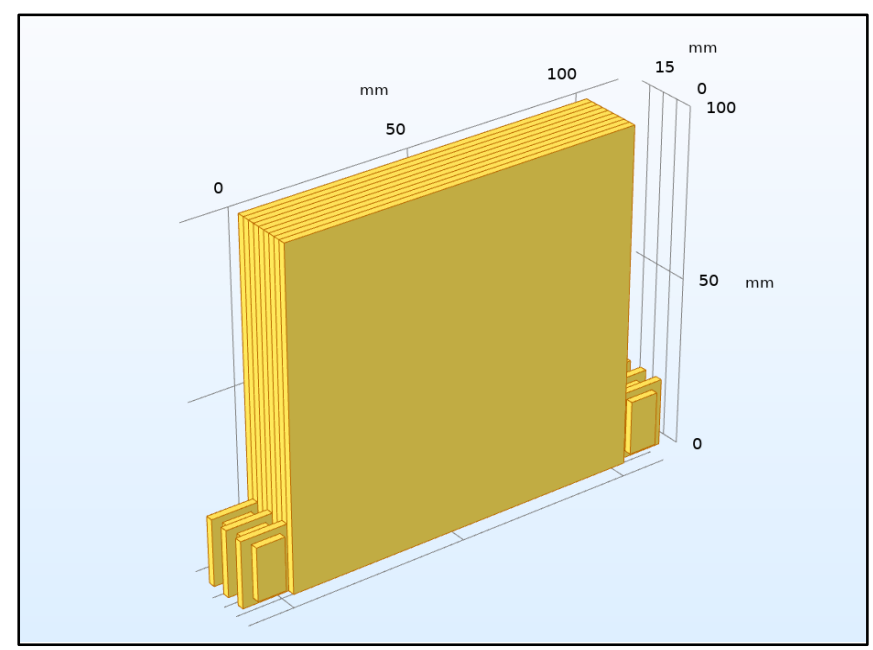

Fig -6: Shows geometry of battery pack with transparency off.

\subsection{Conditions \& Settings}

While designing model some conditions need to be followed \& some settings is required. The model solves for an operational point during a load cycle. Battery temperature is set to the inlet temperature of the cooling fluid i.e. $310 \mathrm{~K}$. The discharge load is about to a $7.5 \mathrm{C}$ rate. Based upon conditions \& settings the design of model is divided into two sub models: (A) Flow model, (B) Heat transfer model. 


\subsubsection{Flow Model Definition}

The model uses the Laminar, incompressible flow interface to solve for the velocity and pressure in the cooling channels.

\subsubsection{Flow Domain Settings}

The flow compartment consists of the two connector channels and the channels in the cooling fins. The cooling fluid is modeled using the material properties of water. The fluid properties are calculated using the inlet temperature as input.

\subsubsection{Flow Boundary Conditions}

Since the cells modeled are the last ones in a larger battery pack, and the geometry being modeled is not the complete pack, the flow compartment has two inlets. The flow through the modeled cooling fin plates enters at Inlet 1, whereas the flow that have passed the cooling fins earlier in the battery pack (that are not included in the model) enter at Inlet 2.

An average flow of $\mathrm{Q}_{\text {fin }}=0.5 \mathrm{~cm}^{3} / \mathrm{s}$ is assumed for each fin in the battery pack. Defining the number of modeled cooling fins as $N_{\text {fins,model }}=3$, and the total number of cooling fins in the pack as $N_{\text {fins,pack }}=50$, the inflow conditions are set to,

$Q_{\text {inlet1 }}=N_{\text {fins,model }} Q_{\text {fin }}$,

$Q_{\text {inlet2 }}=\left(N_{\text {fins,pack }}-N_{\text {fins,model }}\right) Q_{\text {fin }}$.

These inflows are set by using the Laminar inflow condition in the Inlet nodes. At the outlet, atmospheric pressure is applied. All other boundaries are set to no slip conditions.

\subsubsection{Heat Transfer Model Definition}

The model uses the Heat Transfer interface for the temperature field.

\subsubsection{Heat Transfer Domain Settings}

The temperature field is solved for in the flow compartment, the cooling fins, and the batteries. The cooling fins are made of aluminum. The prismatic design of the batteries with the battery sheets primarily extending into the xz-plane results in the following values for the thermal conductivities,

$$
\begin{gathered}
\sum L i k T, i \\
k_{T, x}=-1 L_{i} \\
\sum L_{i} \\
k_{T, y}=\text {------ }, \\
\sum L i / k T, i
\end{gathered}
$$

$$
k_{T, z}=\begin{gathered}
\sum L i k T, i \\
\sum L i
\end{gathered}
$$

Where, $L_{i}$ are the thicknesses of the different layers of the cell, and $k_{T, i}$ the thermal conductivities of the materials constituting these layers. The velocity from the flow model is used as model input for the velocity in the fluid.

\subsubsection{Heat Transfer Boundary Conditions:}

At Inlet 1 an inlet temperature of $310 \mathrm{~K}$ for the cooling fluid is specified. At Inlet 2, a boundary heat flux is applied that takes into account the heat produced in the batteries in the pack that are not included in the model geometry. The average heat source from the battery, denoted $Q_{h}$, and the volume of each battery, $V_{\text {batt }}$, yields the following total heat flux,

$$
q 0=2 Q_{h}\left(N_{\text {fins,pack }}-N_{\text {fins,model }}\right) V_{\text {batt }} * 0.99,
$$

where, the factor 2 stems from the number of batteries per cooling fin, and the factor 0.99 accounts for an assumption of $1 \%$ of the heat being lost to the surroundings before entering the connector channel. An outflow condition is applied at the outlet and symmetry conditions are applied to the surface of the battery facing the part of the battery pack not included in the geometry $(y=0)$. On all other boundaries a heat flux conditions applied with a heat transfer coefficient of $1 \mathrm{~W} /\left(\mathrm{m}^{2} \cdot \mathrm{K}\right)$, thus accounting for some heat being lost to the surroundings due to poor insulation.

\subsection{Solver Sequence}

The model is solved sequentially in three studies, one study for each physics interface. The fluid flow is solved for first, using a constant temperature (the inlet temperature), thereby using the assumption of a uniform temperature and the properties of the cooling fluid being constant in the channels.

To calculate the average heat source from the batteries, a second study containing a time dependent study step is defined solving the $1 \mathrm{D}$ battery model only. The simulation is run from the initial conditions of the battery to a desired time, in this case $60 \mathrm{~s}$. The temperature in the battery model is assumed to be constant and equal to the inlet temperature of the cooling fluid.

Finally, the quasi-stationary temperature of the battery pack, at the desired time in the load cycle, is solved for in a stationary study step contained in a third study, using the flow velocity from the first study and the average heat source taken from the last time step of the time-dependent simulation from the second study. 


\section{RESULTS}

\subsection{Result in Terms of Surface Pressure}

The surface pressure of cooling fins is shown in Fig -7. The pressure at inlet side is more compared to outlet side. The pressure at inlet side is up to 500 Pascal, while at outlet side is up to 100 Pascal.

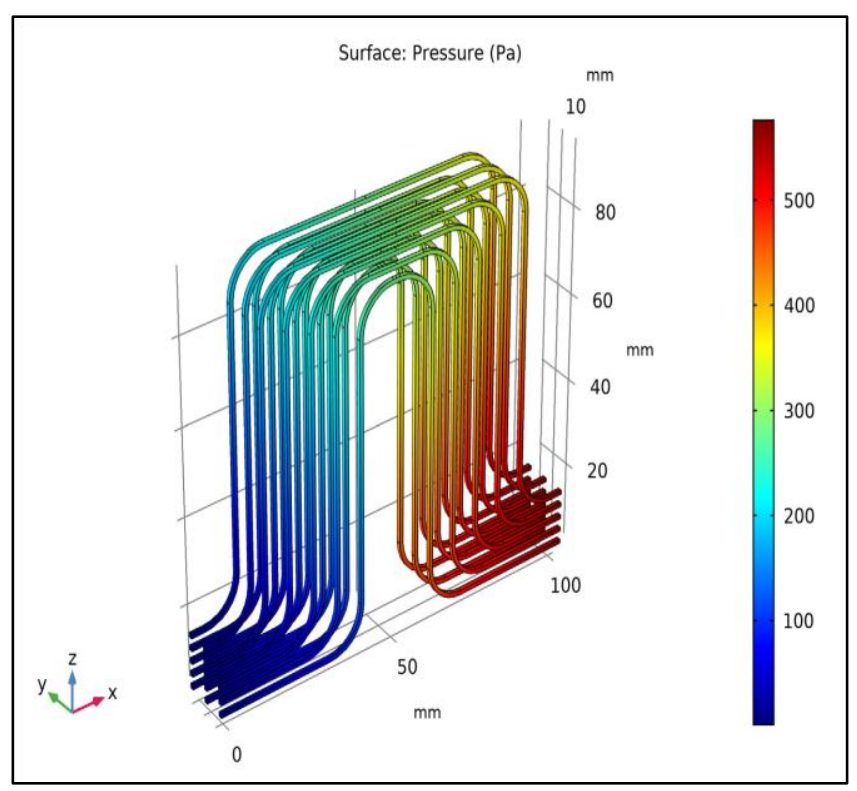

Fig -7: Pressure in the flow compartment.

\subsection{Result in Terms of Velocity}

The velocity magnitude in a cut plane through the middle of one of the cooling fins is shown in Fig - 8 . The velocity magnitude is about $0.2 \mathrm{~m} / \mathrm{s}$ in the middle of the channels. This implies that the residence time for the fluid time in the plates is in the range of only a few seconds, giving support to the assumption that quasi-stationary temperature profile is quickly reached by the battery pack after a load change.

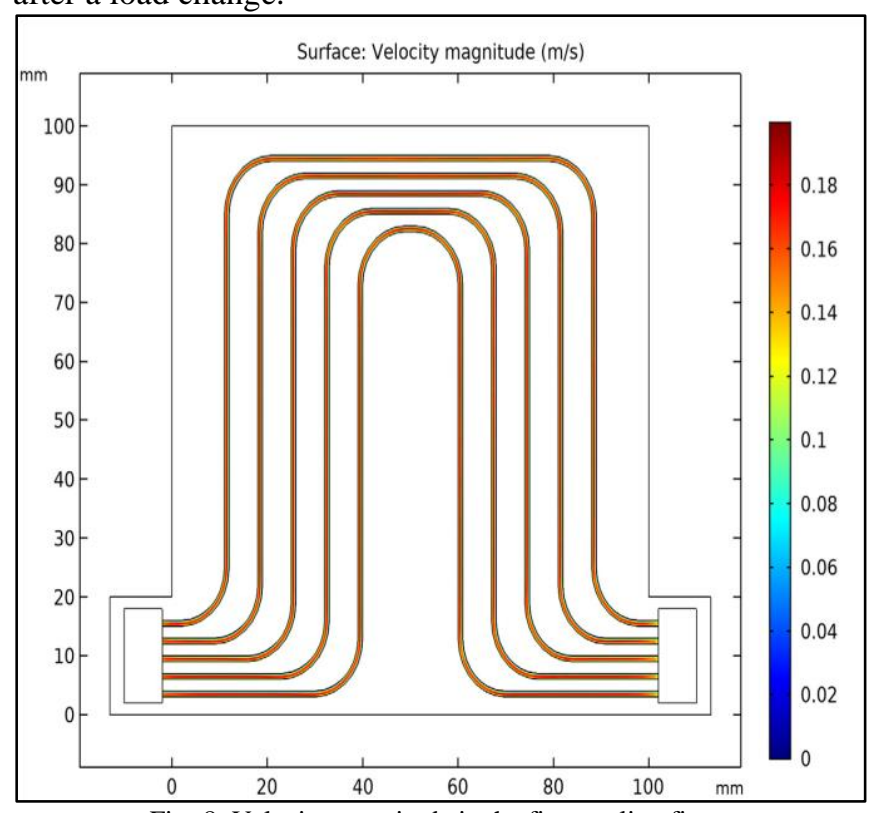

Fig -8: Velocity magnitude in the first cooling fin.

\subsection{Result in Terms of Temperature of Batteries}

Fig -9 , shows the temperature in the batteries. The difference between the highest and lowest temperature in the pack is about $3 \mathrm{~K}$. The temperature variation between different batteries along the y-axis is smaller than the temperature variation within a single battery in the $\mathrm{x} z$-plane.

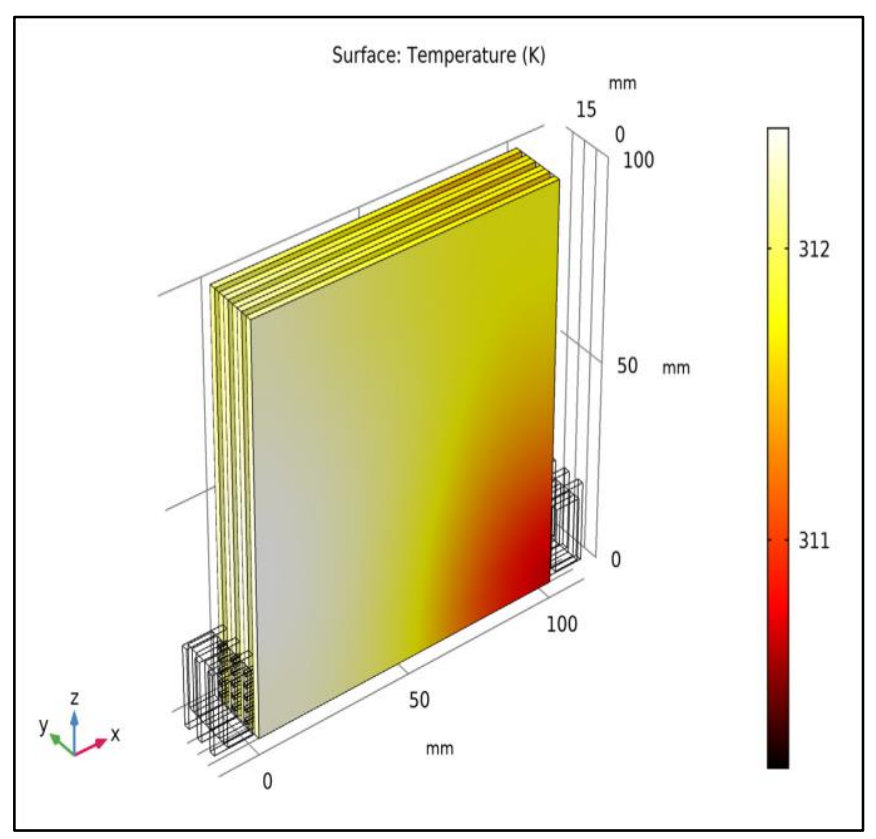

Fig -9: Temperature in the batteries.

\subsection{Result in Terms of Temperature of Coolant}

Fig -10, plots the temperature of the cooling fluid. The temperatures are slightly lower than in the battery.

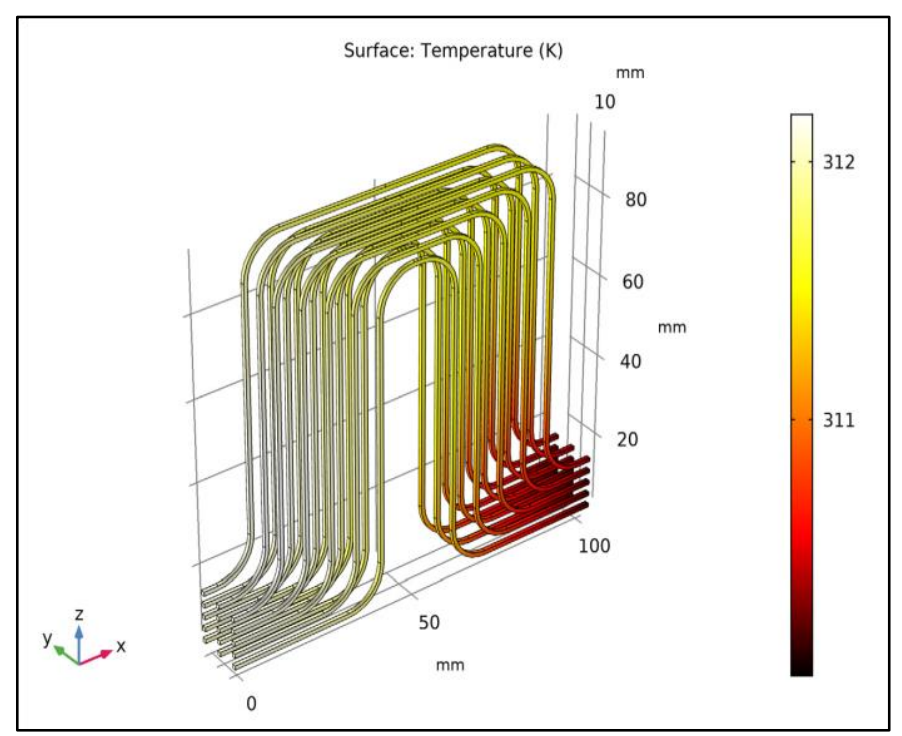

Fig -10: Temperature of the cooling fluid. 


\subsection{D Graph of Results}

Fig -11 , shows the temperature in the second battery by comparing the temperature at the surface facing the cooling fin $(y=4 \mathrm{~mm})$ to the surface facing the third battery $(y=6 \mathrm{~mm})$. The surface towards the cooling fin is cooler, reaching a minimum at the corner towards the inlet. The temperature gradient over the battery is also at its maximum at this point.

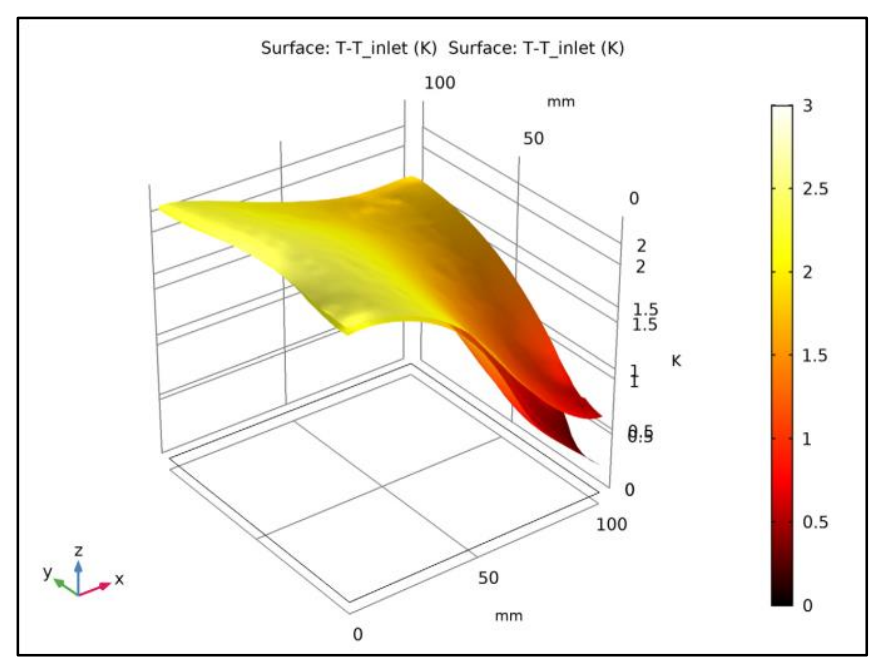

Fig -11: Temperature increase (in relation to the inlet temperature) of the second battery at the surface facing the cooling fin $(y=4 \mathrm{~mm})$ and the surface facing the third battery $(y=6 \mathrm{~mm})$.

\section{CONCLUSION}

$\mathrm{HEV} / \mathrm{EV}$, high voltage battery packs require battery thermal management systems to regulate cell temperatures evenly within the desired operating range. To properly design high voltage battery pack, it is necessary to perform thermal analysis and tests for the cells and the battery pack. To perform thermal analysis software like Comsol Multiphysics can be used in which one can design and study 3D models of battery packs with help of its application. The liquid-cooled lithiumion battery pack system performed as designed. It cooled the cells in a uniform manner with $3 \mathrm{~K}$ of temperature difference in batteries. The current liquid-cooling lithium-ion battery pack system needs to be modified to make possible to choose any coolant liquid.

\section{REFERENCES}

[1] S. S. Zhang, K. Xu, T. R. Jow, "The low temperature performance of Li-ion batteries," Journal of Power Sources, Volume 115(1), pp. 137140 (2003).

[2] Wang, Qingsong ; Ping, Ping; Zhao, Xuejuan; Chu, Guanquan; Sun, Jinhua ; Chen, Chunhua, "Thermal runaway caused fire and explosion of lithium ion battery," Journal of Power Sources, Volume 208, pp. 210-224 (2012)

[3] Wu M. S, Chiang PCJ, "High-rate capability of lithum-ion batteries after storing at elevated temperature, Electrochimica Acta,",Volume 52, pp. 3919-3725 (2007).

[4] Sarre, Guy; Blanchard, Philippe; Broussely, Michel, "Aging of lithium-ion batteries”, Journal of Power Sources, Volume 127, pp. 6571.

[5] Sabbah, Rami; Kizilel, R., Selman, J. R., Al-Hallaj, S., “Active (aircooled) vs. passive (phase change material) thermal management of high power lithium-ion packs: Limitation of temperature rise and uniformity of temperature distribution," Journal of Power Sources, Volume 182, pp. 630-638 (2009) .

[6] A.A. Pesaran, S. Burch, M. Keyser, "An approach for designing thermal management systems for electric and hybrid vehicle battery packs," Fourth Thermal Management Systems Conference and Exhibition, London, UK May 24-27 (1999). 